phlyctenule itself is of tuberculous histological structure or that it contains the tubercle bacillas. Nevertheless, it is now widely believed that, practically speaking, the characteristic lesion occurs only in those who are the subjects of tuberculosis, latent or otherwise.

The main facts that have led to this change of opinion are

1. The frequency with which a family history of tubercle can be obtained from the subjects of phlyctenular disease.

2. The frequent coexistence, along with phlyctenular disease, of other manifestations of tuberculosis-as, for example, enlarged glands or joints; otorrhoea with or without mastoid disease, phthisis pulmonalis, dactylitis, and scrofulodermia.

3. The fact, as shown by the experimental work of J. B. Nias and Leslie Paton, ${ }^{1}$ that the blood of patients suffering from phlyctenular discase behaves in a manner which is typical of a definite tuberculous infection. As the result of examination of the blood in upwards of fifty patients with phlyctonular disease, these authors claim that their observations of the opsonic index go far to support the hypothesis that phlyctenular ulcers are due to the escape of attenuated or dead bacilli from some distant focus, identified or otherwise, of tuberculous disease.

4. The positive result obtained in phlyctenular cases by employing the Koch, Wolff-Eisner-Calmette, von Pirquet, or other specific test for tubercle (Stephenson, Derby, Weekers, etc.).

The observations with von Pirquet's test recently made by us at the Queen's Hospital for Children, London, confirm the view that phlyctenular disease is a tuberculous manifestation, or, at least, that it occurs in tuberculous subjects. During the last few months we have employed the von Pirquet vaccination in 20 cases in children, whose ages have ranged from 2 to 12 years. The series has included five males and fitteen females. Practically every kind of phlyctenular disease was experimented on, varying from recent conjunctival or corneal eruptions to long.standing scars upon the cornea, which bad almost certainly. resulted from former attacks of phlyctenular inflammation. The cutaneous reaction, of course, varied much as regards intensity, but the important point was that a positive result was obtained in every instance. In two cases, howerer, the inoculation was made more than once before a positive result was produced.

It should be added, finally, that a notable proportion of our cases, estimated at 50 per cent., presented more or less obvious signs of tubercle, medical or surgical, while an even larger proportion, estimated at 75 per cent., gave a family history of tubercle.

1 Trans. Ophthalmological REFERENCE. December lst, 1906.

\section{A SERIES OF CASES OF}

\section{CONGENITAL OPHTHALMOPLEGIA EXTERNA} (NUCLEAR PARALYSIS) IN THE SAME FAMILY.

\section{BY HENRY COOPER, B.A., M.R.C.S., L.R.C.P.,} SURGEON, R.N.

This series of cases camé under my notice a short time ago, and is, I think, of sufficient interest for publication.

A youth of 21 (son A. in table) came to me with a small foreign body in his right eye, which was easily removed. He had marked ptosis on both sides, and on further examination I found that all the external eye muscles were paralysed. The only movement. of which the eyeballs were capable was an almost imperceptible tremor when he made an effort to follow a moving object across the field of vision. The pupils both reacted perfectly to light and accommotation, and his sight was normal. He had served his time as a boilermaker, and had never had any difficulty in doing his work. He stated that he "was " born like it," and that his father was similarly affected.

His father I also interviewed, and he gave me all he knew of the family history, which I have embodied in the accompanying table, in which cases are shown in italics.

The father, T. R., aged 57, a sailmaker, stated that he had been affected from birth, but had always had good eyesight.
When working he always held his head on one side, as it came natural to him to use his left eye most, owing to an externa squint in the right eye. He had a]most complete paralysis of both levator palpebrae superioris muscles and complete ( paralysis of all the external eye muscles; except the righ external rectus, which had enough power to cause a small degree of external strabismus. The eyeballs were quite immovable, there being no tremor even when attempting to follow a moving object across, or up and down, the field of vision. The internal ocular muscles were normal and the sight good. He enjoyed good health, and so far as he knew there was no history of any diseases prevalent in the family.

He stated that his father and grandfather were both born with the same affliction, but had no squint, the paralysis being complete save for the internal ocular muscles (grandfather and great-grandfather in table). He had two uncles, one affected, one not. He had two aunts, neither affected. He had two brothers, one affected and one not; the one who was not affected died some years ago in an asylum. Of his own children be said:

I have had six. The first and third died in infancy, and so far as I know were not affected.

The second, my eldest son, is not affected. He is married and has two children who are both unaffected.

My fourth is the boy you have seen. (Son A. in table.)

The fifth, a daughter, is not affected.

The youngest, a boy, is affected, but not so completely as I am he can raise his eyelids a little bit, but his eyeballs are fixed. (Son B. in table.)

It is interesting to note that so far as he can remember 1. No female member of the family has been affected.

2. No case has ever developed after birth, but all have been congenital.

3. The ptosis has been almost complete in all cases except that of his youngest son, who is the first of the series in whom the affliction has appeared in a lesser degree.

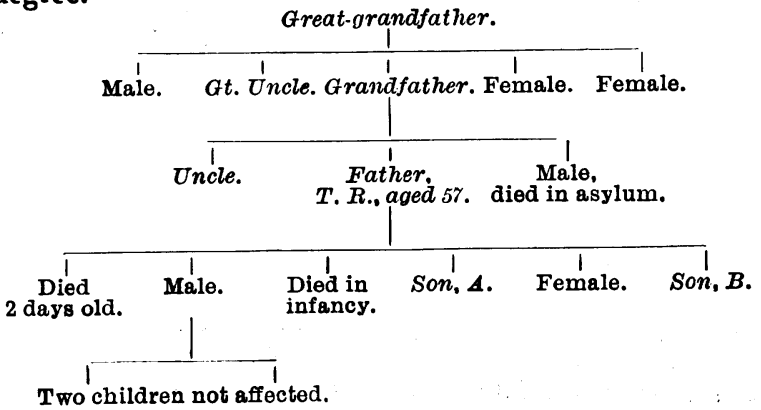

\section{ON MUCOCELE OF THE NASAL SINUSES, AND ITS COMPLICATION BY OPTIC NEURITIS.}

By ROBERT FULLERTON, M.D.,

SURGEON FOR THROAT AND NOSE, OUTDOOR DEPARTMENT, GLABGOW ROYAL INFIRMARY.

DURING the last few years a considerable amount of attention has been given to affections of the nasal sinuses which cause ocular disturbance. In such cases the pathological factor is generally suppuration in the frontal or ethmoidal sinus, or in both, and the symptoms, if not clamant, are tolerably well marked. The three cases which I now record differ from the suppurative variety in that they followed a slow and unobtrusive course ; nevertheless, they present points of interest and practical value, especially in regard to the close and important relationship between these sinuses and the eye.

Two of the patients were referred to me from the Ophthalmic Institution; and I have to thank Dr. Maitland Ramsay for supplying notes on the condition of the ejes, and for allowing me to publish the cases.

$$
\text { CASE I.-Mucocele of the Right Ethmoidal Region causing }
$$
Optic Neuritis.

K. G. aged 20, a laundress, was referred to me on K. G., aged 20, a laundress, was referred to me on
ar. May 28th, 1909, from the Ophthalmic Institution by Dr. Mait-
land Ramsay for nasal treatment. The patient, who looked strong and healthy and gave a good family history, had been employed in a public laundry for the previous six years. For three years she had frequently suffered from headache of the right frontal region, which yielded to powders obtained from her doctor, but she was unconscious of anything being wrong 